\title{
Mammography during Breast Cancer Awareness Month Campaigns in Lomé (Togo): In Relation to 1074 Cases over a Period of 5 Years
}

\author{
Abdoulatif Amadou1, Massaga Dagbe2, Sonia Bignon M. G. Adjadohoun3, Pihou Gbande4, \\ Lantam Sonhaye ${ }^{1}$, Lama Kedigoma Agoda-Koussema ${ }^{5}$, Komlanvi E. Adjenou ${ }^{1}$
}

${ }^{1}$ Radiology Department of University Hospital Center of Campus, Lomé, Togo

${ }^{2}$ Radiology Department of University Hospital Center of de Kara, Kara, Togo

${ }^{3}$ Radiology Department of University Hospital Center of Cotonou, Cotonou, Benin

${ }^{4}$ Radiology Department of Regional Hospital Center of Sokode, Sokode, Togo

${ }^{5}$ Radiology Department of University Hospital Center of Sylvanus Olympio, Lomé, Togo

Email: amadoulatif@yahoo.fr

How to cite this paper: Amadou, A., Dagbe, M., Adjadohoun, S.B.M.G., Gbande, P., Sonhaye, L., Agoda-Koussema, L.K. and Adjenou, K.E. (2021) Mammography during Breast Cancer Awareness Month Campaigns in Lomé (Togo): In Relation to 1074 Cases over a Period of 5 Years. Open Journal of Radiology, 11, 70-80.

https://doi.org/10.4236/ojrad.2021.113007

Received: April 7, 2021

Accepted: August 6, 2021

Published: August 9, 2021

Copyright $\odot 2021$ by author(s) and Scientific Research Publishing Inc. This work is licensed under the Creative Commons Attribution International License (CC BY 4.0).

http://creativecommons.org/licenses/by/4.0/ (c) (i) Open Access

\begin{abstract}
Background: This study aimed to describe the results of mammography done during breast cancer awareness campaigns in Lomé. Methods: This was a retrospective multicenter study which focused on the analysis of mammographic examinations, with or without breast ultrasound, carried out in three (3) clinics in Lomé over a period of five (5) years during the breast cancer awareness month (Pink October) campaigns. We included in our study women of all ages who underwent a mammography during the study period. Additional ultrasound was performed as needed in some women to better characterize a lesion. The parameters studied were socio-demographic data, and aspects of breast lesions. We classified the lesions in order of severity according to the BI-RADS classification. Results: During the study we counted one thousand and seventy-four (1074) women who underwent mammography examinations, corresponding to an average of 214.8 women per year. The median age of the women was 46 years. The most represented age group was $40-49$, constituting $30 \%$ of cases. Mammography was performed on all women and ultrasound was performed on $51.3 \%$ of women. Lesions suspicious for malignancy (BI-RADS IV) and lesions highly suggestive of malignancy (BI-RADS V) represented $3.5 \%$ and $1.9 \%$ of cases respectively, amounting to a prevalence of $5.4 \%$. They occurred more frequently from the age of 30 years with a statistically significant difference $(p=0.02)$. These lesions could be identified on mammograms as masses with irregular shapes and spiculated margins representing $16.1 \%$ and $9.7 \%$ of masses respectively.
\end{abstract}


On ultrasound, these were solid masses with irregular and ill-defined borders, representing $25.2 \%$ and $5.2 \%$ of solid masses respectively. Lesions suspicious for malignancy were most often found in the UOQ (upper outer quadrant) in $70 \%$ of cases. Conclusion: Mammography screening for breast cancer remains a necessity in our community, even if the rate of cancer detected remains low. It allows for early diagnosis of cancers, promoting better management.

\section{Keywords}

Screening, Breast Cancer, Woman, Mammography, Awareness Campaign, Lomé

\section{Introduction}

Breast cancer is becoming more common and poses a real public health challenge in both developed and developing countries. It is the most common cancer in women in the world [1]. It is estimated that there were 14.1 million new cases and 8.2 million deaths from breast cancer in 2012 [2]. It is the most frequently diagnosed cancer in women in 140 out of the 184 countries included in GLOBOCAN worldwide, with an increasing incidence in most parts of the world and much higher mortality in poor countries due to lack of early diagnosis and access to treatment [3].

In sub-Saharan Africa, breast cancer is the second most common cancer after cervical cancer in women [3]. In Togo, it represents $12.4 \%$ of all cancers identified, with an annual frequency of 22.5 cases on average and ranks second among cancers in women after cervical cancer (16.2\%) [4] [5]. Thus, for some years now, organized or individual screening has been carried out for the purpose of reaching a diagnosis in the preclinical phase. The breast cancer screening test can be a clinical and/or radiological examination applied to a target population of women. In Togo, as in most African countries, organized screening is practically absent. To partially resolve this lack of organized screening, since 2009, awareness campaigns and mammographic screening for breast cancer have been organized in Togo at affordable prices each October and called "Octobre rose" (literally, Pink October). No study has so far evaluated the results of mammography done during these screening campaigns; hence the interest of our study is to describe the results of mammography performed in the course of cancer awareness and screening campaigns during Pink October in Lomé (Togo).

\section{Methods}

\subsection{Type and Period of Study}

This was a retrospective study carried out in the course of breast cancer awareness and screening campaigns during the month of October, from 2014 to 2018, i.e. over a period of 5 years. 


\subsection{Study Site}

The study took place in the medical imaging department of Campus the University Hospital Center in Lomé, Togo.

\subsection{Patients}

We included in our study women of all ages who underwent a mammography during the study period. Additional ultrasound was performed as needed in some women to better characterize a lesion.

Awareness-raising consisted of specialist conferences and radio and television broadcasts in which women were informed about the existence of breast cancer and its early as well as late clinical manifestations.

\subsection{Data Collection}

Consultation fairs were organized consisting of clinical examination of women's breasts and requests for mammography examinations. Women were also given the option of having a mammogram without prior clinical examination.

The mammography procedure consisted of acquiring two standard projections, namely the craniocaudal (CC) and mediolateral oblique (MLO) projections. The lateral projection was performed at the request of the radiologist to better specify the topography of a lesion.

Ultrasound was performed as needed to better analyze a lesion detected on mammography.

\subsection{Main Variables}

The parameters studied were age, sex, history, breast density, lesion morphology and topography. We classified the lesions in order of severity according to the BI-RADS classification (BIRAD I: normal examination; BI-RADS II: benign lesion; BI-RADSIII: probably benign lesion; BI-RADS IV: lesion suspicious for malignancy; BI-RADS V: malignant lesion).

Breast density was classified: type A: almost entirely fatty breasts; type B: breasts with scattered areas of fibroglandular density; type C: heterogeneously dense breast; type D: extremely dense breast.

\subsection{Statistical Analysis}

Data entry was made with EpiData Software version 3.1 and analyzed with EpiInfo2000 software version 3.5.4 with statistical tests (Chi-Square test), the significance level of $p$-value being $<0.05$.

The informed consent of the women had been obtained for this study to be carried out.

\section{Results}

We identified 1074 women who underwent mammography over a period of 5 years, representing an average of 214.8 women per year. 
The mean age of the women was 46 , and $60.7 \%(n=652)$ of them were under the age of 50 .

$3.4 \%(n=37)$ of the women had a family history of breast cancer.

\subsection{Mammography}

Mammography was performed in all patients $(\mathrm{n}=1074)$ with 245 examinations revealing pathologies, representing $22.8 \%$ of cases.

The lesions found were mostly calcifications followed by nodular opacities representing 39.6\% ( $n=97)$ and $38.6 \%(n=93)$ of cases respectively (Table 1$)$.

Concerning calcifications, we found $65 \%$ of them $(n=63)$ being macrocalcifications and $35 \%$ of them $(n=34)$ being microcalcifications (Figure 1) (Table 2).

Nodular opacities having an oval shaped and those with smooth borders were the most common, representing $77.4 \%(\mathrm{n}=72)$ and $74.2 \%(\mathrm{n}=69)$ of cases respectively (Figure 2) (Table 3).

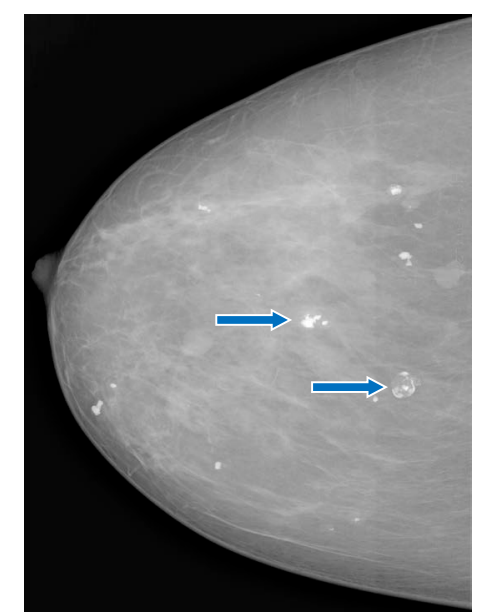

Figure 1. Front mammogram showing scattered calcifications (macro and microcalcifications) in the breast.

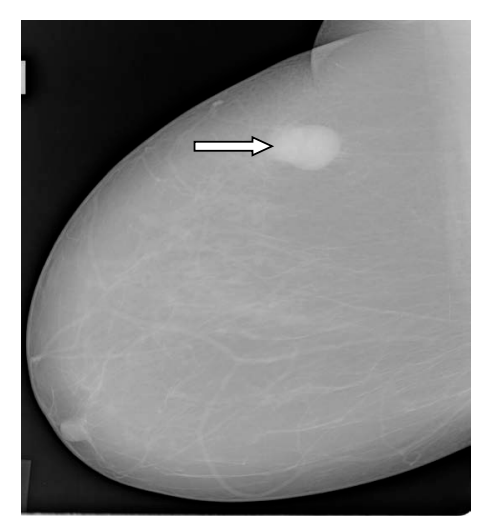

Figure 2. Profil mammogram showing an oval opacity with regular contours in the breast (BIRADS II). 
Table 1. Distribution of mammographic lesions.

\begin{tabular}{ccc}
\hline & $\mathrm{n}$ & $\%$ \\
\hline Calcifications & 97 & 39.6 \\
Nodular opacities & 93 & 38 \\
High-density masses & 28 & 11.4 \\
Intramammary lymph nodes & 18 & 7.3 \\
Skin thickening & 15 & 6.1 \\
Nipple retraction & 8 & 3.3 \\
Architectural distortion & 2 & 0.8 \\
\hline
\end{tabular}

Table 2. Distribution of calcifications.

\begin{tabular}{lccc}
\hline & n & $\%$ \\
\hline Macrocalcification & 63 & $65 \%$ \\
\hline Annular & 26 & \\
Vascular & 28 & \\
Popcorn & 9 & \\
\hline Microcalcification & & 34 & $35 \%$ \\
\hline & Too fine for precizing the shape & 13 & \\
& Regularly punctiform & 11 & \\
& Annular & 7 & \\
& Irregularly punctiform & 2 & \\
& Vermicular & 1 & \\
\hline
\end{tabular}

Table 3. Distribution of nodular opacities according to morphology.

\begin{tabular}{lccc}
\hline & & $\mathbf{n}$ & $\%$ \\
\hline Margins & Smooth & 69 & $74.2 \%$ \\
& Irregular & 15 & $16.1 \%$ \\
& Spiculated & 9 & $9.7 \%$ \\
\hline Shape & Oval & 72 & $77.4 \%$ \\
& Round & 12 & $12.9 \%$ \\
& Polycyclic & 9 & $9.7 \%$ \\
\hline
\end{tabular}

\subsection{Ultrasonography}

Ultrasound was performed in 551 women, with 218 examinations (36.9\%) revealing pathologies.

Among the lesions discovered, there was a predominance of with $62 \%(\mathrm{n}=$ 135) followed by cystic lesions with $19.2 \%(\mathrm{n}=42)$ (Table 4$)$.

Among the nodules found, $25.2 \%(\mathrm{n}=34)$ presented irregular borders and $5.2 \%(n=07)$ ill-defined borders (Table 5). 
Table 4. Distribution of ultrasound lesions.

\begin{tabular}{ccc}
\hline & $\mathbf{n}$ & $\%$ \\
\hline Solid nodules & 135 & 62 \\
Cystic nodules & 42 & 19.2 \\
Bilateral galactophoric ectasia & 25 & 11.4 \\
Intramammary lymph nodes & 12 & 5.5 \\
Calcifications & 18 & 9.1 \\
Lipoma & 6 & 2.7 \\
Mastosis & 5 & 2.3 \\
Abscess & 4 & 1.8 \\
Mammary dystrophy & 4 & 1.8 \\
Mastitis & 2 & 0.9 \\
Keloid & 1 & 0.4 \\
Foreign body & 1 & 0.4 \\
\hline
\end{tabular}

Table 5. Distribution of solid nodules on ultrasound.

\begin{tabular}{cccc}
\hline & & $\mathbf{n}$ & $\%$ \\
\hline \multirow{2}{*}{ Margins } & Smooth & 52 & 38.6 \\
& Irregular & 42 & 31 \\
& Ill-defined & 7 & 25.2 \\
Content & Hypoechoic & 127 & 5.2 \\
\hline \multirow{2}{*}{ Shape } & Hyperechoic & $\mathbf{8}$ & 94 \\
& Oval & 107 & 6 \\
\hline Echogenicity & Polycyclic & 17 & 79.2 \\
& Hound & 11 & 12.6 \\
& Heterogenous & $\mathbf{5 8}$ & 8.2 \\
\hline Major axis & Transverse & $\mathbf{1 1 2}$ & 57 \\
& Vertical & $\mathbf{1 7}$ & 43 \\
\hline
\end{tabular}

\subsection{Mammography and Ultrasonography Assessment}

\section{- Topography of lesions}

The lesions were most often located in the upper-external quadrant $(31.8 \%)$ (Table 6).

\section{- Classification of lesions}

Lesion suspicious of malignancy (BI-RADS IV) (Figure 2) and malignant (BI-RADS V) (Figure 3) lesions represented 3.5\% $(\mathrm{n}=38)$ and $1.9 \%(\mathrm{n}=20)$ respectively (Table 6).

\section{- Correlations of lesions}

\section{Age}




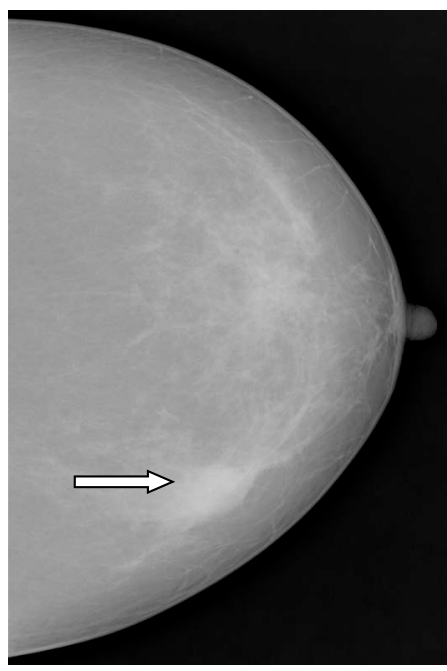

Figure 3. Front mammogram showing an oval opacity with irregular contours in the breast (BIRADS IV).

Table 6. Distribution of lesions according to age.

\begin{tabular}{ccccccccc}
\hline & $<30$ & $\mathbf{3 0 - 3 9}$ & $\mathbf{4 0 - 4 9}$ & $\mathbf{5 0 - 5 9}$ & $\mathbf{6 0 - 6 9}$ & $\mathbf{7 0 - 7 9}$ & $\mathbf{2 0 0}$ & Total \\
\hline BI-RADS I & 64 & 171 & 229 & 206 & 67 & 19 & 2 & $\mathbf{7 5 8}$ \\
BI-RADS II & 24 & 39 & 58 & 45 & 26 & 13 & 2 & $\mathbf{2 0 7}$ \\
BI-RADS III & 2 & 11 & 20 & 14 & 3 & 1 & 0 & $\mathbf{5 1}$ \\
BI-RADS IV & 1 & 11 & 11 & 8 & 1 & 4 & 2 & $\mathbf{3 8}$ \\
BI-RADS V & 0 & 5 & 6 & 3 & 5 & 1 & 0 & $\mathbf{2 0}$ \\
Total & $\mathbf{9 1}$ & $\mathbf{2 3 7}$ & $\mathbf{3 2 4}$ & $\mathbf{2 7 6}$ & $\mathbf{1 0 2}$ & $\mathbf{3 8}$ & $\mathbf{6}$ & $\mathbf{1 0 7 4}$ \\
\hline
\end{tabular}

$P=0.002$.

Lesions classified as BI-RADS IV (Figure 3), and BI-RADS V were most frequently found before the age of 50 , respectively in $60.5 \%(\mathrm{n}=23)$ and $55 \%$ of cases $(\mathrm{n}=11)$ (Table 6). This difference was statistically significant with $p=0.02$.

\section{Topography}

Lesions suspicious of malignancy (BI-RADS IV) were found in the right breast in 52.6\% $(\mathrm{n}=20)$ of cases and malignant lesions (BI-RADS V) affected both breasts in equal proportions $(50 \%)(\mathrm{n}=10)$ (Table 7).

\section{Breast density}

Lesions suspicious of malignancy (BI-RADS IV) and malignant (BI-RADS V) lesions were more often found in homogeneous (Type A) and heterogeneous (Type B) fatty breasts in $86.8 \%(\mathrm{n}=33)$ and $95 \%(\mathrm{n}=19)$ of cases, respectively (Table 8).

\section{Discussion}

The mean age in our study was 46 years and $60.7 \%(n=652)$ of the women were less than 50 years old. Prevalence of BI-RADS IV lesions and BI-RADS V lesions 
Table 7. Distribution of lesions according to the affected breast.

\begin{tabular}{cccc}
\hline & Right & Left & Total \\
\hline BI-RADS II & 108 & 89 & 207 \\
BI-RADS III & 25 & 26 & 51 \\
BI-RADS IV & 20 & 18 & 38 \\
BI-RADS V & 10 & 10 & 20 \\
Total & 133 & 107 & 316 \\
\hline
\end{tabular}

Table 8. Distribution of lesions according to breast density.

\begin{tabular}{cccccc}
\hline & TYPE A & TYPE B & TYPE C & TYPE D & Total \\
\hline BI-RADS I & 290 & 322 & 110 & 36 & $\mathbf{7 5 8}$ \\
BI-RADS II & 63 & 93 & 31 & 20 & $\mathbf{2 0 7}$ \\
BI-RADS III & 22 & 17 & 11 & 1 & 51 \\
BI-RADS IV & 17 & 16 & 4 & 1 & $\mathbf{3 8}$ \\
BI-RADS V & 5 & $\mathbf{1 4}$ & 1 & 0 & $\mathbf{2 0}$ \\
Total & $\mathbf{3 9 7}$ & $\mathbf{4 6 2}$ & $\mathbf{1 5 7}$ & $\mathbf{5 8}$ & $\mathbf{1 0 7 4}$ \\
\hline
\end{tabular}

was $3.5 \%(\mathrm{n}=38)$ and $1.9 \%(\mathrm{n}=20)$ respectively. In a similar study by Frikha et al. [6], the average age was 51.56 years, with a predominance of lesions in the age group $45-49$, with respectively $7.81 \%$ prevalence of lesions suspicious of malignancy and $0.23 \%$ prevalence of malignant lesions.

Screening of women aged less than 50 years as done in our study is contrary to available data in literature [7] [8] which recommend screening in the age group of 50 to 74 years. Screening that age group can be controversial in African countries especially because the incidence of breast cancer is believed to be increasing in young women in Africa [4] [9] [10]. Indeed, in our study, the risk of cancer (lesions classified as BI-RADS IV and BI-RADS V) was higher in women aged 40 to 49 years with a statistically significant difference. Our study confirms that of Ben Abdallah [10] in Tunisia who had shown that the average age of onset of breast cancer in African women is about ten years lesser when compared to female patients in the western world. Thus, breast cancer affects $50 \%$ of women aged between 40 and 54 years and screening the age group 50 - 74 would overlook a population that harbors $34.4 \%$ of cases related to this cancer [11]. Some studies show that the incidence of the disease is significantly high from the age of 40 , with a reduction in the mortality rate in the event of screening similar to that recorded for women aged 50 to 69 years, thereby justifying routine screening in this age group [12]. But, there is little data available on the age group under 50 years in large experimental trials.

In our study, we noted that $20 \%$ of breasts were dense breasts (types C and D under BI-RADS reporting system). Séradour [13] in France observed that heterogeneously dense breasts and extremely dense breasts represented $28 \%$ of the population between 50 and 74 years old that was screened. Breast density is 
thought to be an independent risk factor for the occurrence of breast cancer, even during screening [13] [14]: the relative risk (RR) of finding cancer during screening is 4.5 for women who have extremely dense breasts as compared to those who have breasts of lesser density. In our study, there was no significant relationship between breast cancer risk and breast density.

Breast microcalcifications are lesions found in approximately $30 \%$ of malignant breast lesions and are the early signs of subclinical malignant lesions of the breast in more than half of cases [15]. They are the early signs of $85 \%$ to $95 \%$ of cases of ductal carcinoma during screening campaigns [15]. In our population sample, we found a $3.16 \%$ prevalence of microcalcifications. In their study, Ngou-Nve-Ngou et al. [16] found 79\% prevalence of microcalcifications in a sample of patients who presented a subclinical breast lesion defined as suspicious after mammography.

The upper-external quadrant was the most frequently affected quadrant in the event of pathology, i.e. $31.8 \%$ of cases. This topography is linked to the higher density of fibroglandular tissue in the central and upper-outer part of the breast [17].

The occurrence of tumor (malignant or benign) of the breast did not seem to have anything to do with laterality. The right breast was the most often affected in our population sample (55\%) in cases of a solid nodule. In the study of Ngou-Mve-Ngou et al. [16], the left breast was the most often affected (62.7\%), without a significant relationship.

\section{Conclusion}

Considering its prevalence and mortality rate, breast cancer is a major public health problem, hence the need for clinical and mammographic screening for better management. Mammography coupled with ultrasound helped in detecting lesions suspicious of malignancy and lesions highly suggestive of malignancy in $3.5 \%$ and $1.9 \%$ of cases, respectively. Clinical examination of the breasts supplemented by mammography (whether or not coupled with ultrasound) therefore remains essential means for the early detection of breast cancer. Effective sensitization of the Togolese population, as well as the regular setting up of mass screening campaigns for breast cancer throughout the entire territory would contribute to early detection of breast lesions and therefore to an obvious reduction in mortality due to breast cancer.

\section{Acknowledgements}

The authors acknowledge all the cancer associations in Togo and all associated personnel that contributed to the completion of this study.

\section{Conflicts of Interest}

The authors declare no conflicts of interest regarding the publication of this paper. 


\section{References}

[1] Wilson, J.M. and Jungner, G. (1970) Principes et pratiques du dépistage des maladies. Cahiers de santé publique, OMS.

[2] Ferlay, J., Soerjomataram, I., Dikshit, R., Eser, S., Mathers, C., Rebelo, M., et al. (2015) Cancer Incidence and Mortality Worldwide: Sources, Methods and Major Patterns in GLOBOCAN 2012. International Journal of Cancer, 136, 359-386. https://doi.org/10.1002/ijc.29210

[3] Ly, M., Antoine, M., André, F., Callard, P., Bernaudin, J.F. and Diallo, D.A. (2011) Le cancer du sein chez la femme de l'Afrique sub-saharienne: État actuel des connaissances. Bulletin du Cancer, 98, 797-806. https://doi.org/10.1684/bdc.2011.1392

[4] Darré, T., Amégbor, K., Sonhaye, L., Kouyate, M., Aboubaraki, A., N’timom, B., Bassowa, A., Fiagnon, K., Adama, R., Klu, S. and Napo-Koura, G. (2013) Profil histo-épidémiologique des cancers du sein. A propos de 450 cas observés au CHU de Lomé. Médecine d'Afrique Noire, 60, 53-58.

[5] Darré, T., Walla, A., Kpatcha, T.M., Aboubakari, A., Maneh, N., Koulinga, M., et al. (2016) Cancers in the Elderly Seen in Anatomical Pathology Laboratory in Lomé, Togo. Open Journal of Pathology, 6, 26-31. https://doi.org/10.4236/ojpathology.2016.61005

[6] Frikha, M., Yaiche, O., Elloumi, F., Mnejja, W., Slimi, L., et al. (2013) Résultats d'un essai pilote de dépistage de cancer du sein par mammographie dans la région de Sfax, Tunisie. Journal de Gynécologie Obstétrique et Biologie de la Reproduction, 42, 252-261. https://doi.org/10.1016/j.jgyn.2013.01.007

[7] Binder-Foucard, F., Belot, A., Delafosse, P., et al. (2013) Estimation nationale de l'incidence et de la mortalité par cancer en France entre 1980 et 2012. Étude à partir des registres des cancers du réseau Francim. INVS.

[8] République Française, Loi nº 2004-806 du 9 août 2004 relative à la politique de santé publique, JORF du 11 août 2004.

[9] Zaki, H.M., Garba-Bouda, O., Garba, S.M. and Nouhou, H. (2013) Profil épidémiologique et anatomopathologique du cancer du sein au Niger. Journal of African Cancer, 5, 185-191.

[10] Ben Abdallah, M. (2010) Cancer du sein: Épidémiologie, prise en charge, résultats thérapeutiques et coût. Registre de l'Institut Salah-Azaïz, Tunis, 2005.

[11] Maalej, M., Hentati, D., Messai, T., et al. (2008) Breast Cancer in Tunisia in 2004: A Comparative Clinical and Epidemiological Study. Bulletin du Cancer, 95, 5-9.

[12] Smith, R.A., Saslow, D., Sawyer, K.A., Burke, W., Costanza, M.E. and Evans, W.P. (2003) American Cancer Society Guidelines for Breast Cancer Screening: Update 2003. CA: A Cancer Journal for Clinicians, 53, 141-169. https://doi.org/10.3322/canjclin.53.3.141

[13] Seradour, B. (2004) Impact de la densité mammaire sur le dépistage. $26^{\text {ème }}$ journées de la SFSPM, Nancy.

[14] Boyd, N.F., Guo, H., Martin, L.J., et al. (2007) Mammographic Density and the Risk of Detection of Breast Cancer. The New England Journal of Medicine, 356, 227-236. https://doi.org/10.1056/NEJMoa062790

[15] Henrot, P., Leroux, A., Barlier, C. and Génin, P. (2013) Les microcalcifications mammaires: Quelles lésions en anatomie pathologique? Diagnostic and Interventional Imaging, 95, 145-157. https://doi.org/10.1016/j.jradio.2013.12.007

[16] Ngou-Mve-Ngou, J.P., Mayi-Tsonga, S., Diallo Owono, F.K., Ngo'o Nze, S. and 
Ondo N’dong, F. (2009) Lésions infra cliniques du sein à libreville (GABON): Etude rétrospective de 174 cas. Clinics in Mother and Child Health, 6, 1003-1006.

[17] Gest, J., et al. (1975) Cancer du sein étiologie et histoire naturelle. EMC Paris, Gynéco, 4, 865. 